\title{
Knockdown of Livin inhibits growth and invasion of gastric cancer cells through blockade of the MAPK pathway in vitro and in vivo
}

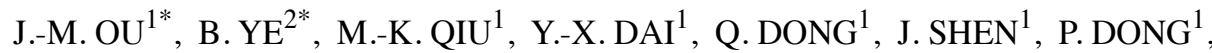 \\ X.-F. WANG ${ }^{1}$, Y.-B. LIU ${ }^{1}$, Z.-W. QUAN ${ }^{1}$ and Z.-W. FEI ${ }^{3}$ \\ ${ }^{1}$ Department of General Surgery, Xinhua Hospital Affiliated to Shanghai Jiaotong University School of Medicine, \\ Shanghai 200092; ${ }^{2}$ Department of Orthopedics, Shanghai No. 1 Rehabilitation Hospital, \\ Shanghai 200090; ${ }^{3}$ Department of General Surgery, Xinhua Hospital (Chong Ming) \\ Affiliated to Shanghai Jiaotong University School of Medicine, Shanghai 202150, P.R. China
}

Received September 7, 2013; Accepted October 21, 2013

DOI: $10.3892 /$ ijo.2013.2171

\begin{abstract}
Livin, a novel member of the human inhibitors of apoptosis protein family, has been shown to be critical for tumor progression and poor prognosis for several types of malignancies. However, limited reports exist regarding the biological functions of Livin in human gastric cancer (GC). The present study investigated the clinical significance of Livin and caspase-3 (CAS-3) in human GC using immunohistochemistry assay, and explore the potential using RNA interference to knockdown Livin expression, including the subsequent effects on tumor growth and invasion in GC cells in vitro and in vivo. Our results showed that the rate of positive expression of Livin was significantly higher in GC tissues compared to that in adjacent non-cancer tissues (ANCT) (64.1 vs. 30.8\%, $\mathrm{P}<0.001)$, while CAS-3 was lower in $\mathrm{GC}$ tissues than in ANCT (33.3 vs. 66.7\%, $\mathrm{P}=0.001)$. Livin expression was positively correlated with tumor differentiation and lymph node metastases $(\mathrm{P}=0.009 ; \mathrm{P}=0.007)$, while CAS-3 was negatively correlated with them $(\mathrm{P}=0.036 ; \mathrm{P}=0.002)$ in patients with GC. Furthermore, knockdown of Livin inhibited cell proliferative activities and invasive potential, and induced cell in situ apoptosis in GC cells, accompanied with decreased expression of p38 MAPK, VEGF and MMP-2 and increased expression of CAS-3. In addition, the tumor volumes in the SGC7901 subcutaneous nude mouse model treated with Lv-shLivin was significantly smaller compared to those of the PBS group $(\mathrm{P}<0.01)$. Taken together, our findings indicate that the expression of Livin is increased in human GC and
\end{abstract}

Correspondence to: Professor Zhe-Wei Fei, Department of General Surgery, Chongming Branch Hospital, Xinhua Hospital Affiliated to Shanghai Jiaotong University School of Medicine, Shanghai Chongming County, 25 Nan men gang Road, Shanghai 202150, P.R. China

E-mail: zheweifei@163.com

"Contributed equally

Key words: Livin, gastric cancer, growth, invasion, apoptosis correlates with tumor differentiation and lymph node metastases, while knockdown of Livin inhibits cell growth and invasion through blockade of the MAPK pathway in GC cells, suggesting that Livin may be a potential therapeutic target for the treatment of GC.

\section{Introduction}

Gastric cancer (GC) is one of the most common malignancies worldwide, with an estimated 934,000 cases reported globally in 2002, and is the second most common cause of death from cancer. The prognosis of GC is poor with an estimated relative 5-year survival rate of $<20 \%$ (1). GC is a genetic disease developing from a multi-step process. Single or multiple mutations in genes related to growth control, invasion and metastasis form the molecular genetic basis of malignant transformation and tumor progression (2). Therefore, identification of key genes and targets related to tumorigenesis is crucial for diagnosis and prevention of GC.

Apoptosis plays a pivotal role in sustaining proper tissue development and homeostasis. Evading apoptosis by cancer cells is a part of their adaption to microenvironment and therapies. Pro-survival molecules including Livin can protect tumor cells from apoptosis and mediate metastatic processes, thus enhancing aggressive phenotype (3). Livin, an identified member of the inhibitor-of-apoptosis protein (IAP) family of anti-apoptosis proteins, is expressed in a variety of tumors including melanoma, neuroblastoma, mesothelioma and osteosarcoma (4-6). A high level of Livin protein expression plays a role in the progression of melanoma and correlates with survival and a poor prognosis (7). Overexpression of Livin stimulates cell proliferation and inhibits chemical induced apoptosis in bladder cancer, suggesting it as a promising marker to identify the relapse risk in bladder cancer (8). Livin expression also increases resistance to apoptotic stimuli, and contributes significantly to the proliferation and invasive capacity of hepatocellular carcinoma (HCC) cells (9), while targeted inhibition of Livin by peptides represents a viable approach for the apoptotic sensitization and growth inhibition of tumor cells (10). Thus, targeting Livin may offer a therapeutic benefit in apoptosis-inducing treatment. 
Livin plays an important role in drug resistance and radiation sensitivity of some cancers. It is highly expressed in colon cancer cells resistant to several antitumor drugs and knockdown of the expression reverses drug resistance phenotype of tumor cells (11). Livin increases resistance to doxorubicin and etoposide in MYCN oncogene amplified neuroblastoma (12). Overexpression of Livin inhibits the activation of caspase- 3 and leads to resistance to cisplatin, while Livin knockdown enhances its sensitive in colorectal cancer (CRC) cells (13). The IAP Livin is also an important molecule in anti-radiotherapy, and Livin-specific gene silencing is likely to be an effective means to enhance radiation sensitivity of lung cancer (14). These studies highlight the potential of Livin for cancer therapy.

However, some studies have shown that Livin plays a dual role in tumorigenicity. Livin $\alpha$ promotes tumor initiation, while the growth of tumors originating from cells expressing Livin $\beta$ is inhibited (15). Livin expression does not correlate with pathological or clinical parameters and are not predictive of patient outcome $(16,17)$. Thus, we need to explore further the clinical significance and function of Livin in GC. We hypothesized that Livin expression correlated with pathological or clinical parameters of patients with GC, and knockdown of Livin suppressed cell growth and invasion, and induced cell apoptosis in GC cells via inhibition of the MAPK pathway.

\section{Materials and methods}

Materials. The human SGC-7901 GC cell line used in the experiments was from Institute of Biochemistry and Cell Biology (Shanghai, China). Lv-shLivin, negative control vector and virion-packaging elements were from Genechem (Shanghai, China). The primers of Livin, VEGF and CAS-3 were synthesized by ABI Prism (USA). All antibodies were from Santa Cruz Biotechnology (Santa Cruz, CA, USA).

Drugs and reagents. Dulbecco's modified Eagle's medium (DMEM) and fetal bovine serum (FBS) were from Thermo Fisher Scientific Inc. (Waltham, MA, USA); TRIzol reagent and Lipofectamine 2000 were from Invitrogen (Carlsbad, CA, USA); M-MLV Reverse Transcriptase was from Promega (Madison, WI, USA); SYBR Green Master Mixture was from Takara (Otsu, Japan). ECL-PLUS/kit was from GE Healthcare (Piscataway, NJ, USA). In-situ cell death kit was from Boehringer-Mannheim (Germany).

Clinical samples and data. Human GC tissues and corresponding ANCT were obtained from biopsy prior to chemotherapy in a total of 78 consecutive cases of GC admitted in our hospital from January 2008 to December 2011. The study was approved by Medical Ethics Committee of Shanghai Jiaotong University and written informed consent was obtained from the patients or their parents before sample collection. Two pathologists respectively reviewed all of the cases.

Immunohistochemical (IHC) staining. Anti-Livin and CAS-3 antibodies were used for IHC detection of the expression of Livin and CAS-3 proteins in tissue microarrays. Tissue microarray sections were processed for IHC analysis of Livin and
CAS-3 protein as follows: IHC examinations were carried out on 3-mm thick sections. For anti-Livin and CAS-3 IHC, unmasking was performed with $10 \mathrm{mM}$ sodium citrate buffer, $\mathrm{pH} 6.0$, at $90^{\circ} \mathrm{C}$ for $30 \mathrm{~min}$. For anti-Livin and CAS-3 IHC, antigen unmasking was not necessary. Sections were incubated in $0.03 \%$ hydrogen peroxide for $10 \mathrm{~min}$ at room temperature, to remove endogenous peroxidase activity and then in blocking serum $(0.04 \%$ bovine serum albumin, A2153, Sigma-Aldrich, Shanghai, China and 0.5\% normal goat serum X0907, Dako Corp., Carpinteria, CA, USA, in PBS) for $30 \mathrm{~min}$ at room temperature. Anti-Livin and CAS-3 antibodies were used at a dilution of 1:200. The antibodies were incubated overnight at $4^{\circ} \mathrm{C}$. Sections were then washed three times for $5 \mathrm{~min}$ in PBS. Non-specific staining was blocked with $0.5 \%$ casein and $5 \%$ normal serum for $30 \mathrm{~min}$ at room temperature. Finally, staining was developed using diaminobenzidine substrate and sections were counterstained with hematoxylin. Normal serum or PBS was used to replace anti-Livin and CAS-3 antibodies in negative controls. Livin and CAS-3 expression was semiquantitatively estimated as the total IHC staining score. The proportion score reflected the fraction of positive staining cells (score $0,<5 \%$; score $1,5-10 \%$; score $2,10-50 \%$; score 3 , $50-75 \%$; score $4,>75 \%$ ), and the intensity score represented the staining intensity (score 0 , no staining; score 1, weak positive; score 2 , moderate positive; score 3 , strong positive). Finally, a total expression score was given ranging from 0 to 12 . Based on the analysis in advance, Livin and CAS-3 were regarded as negative expression in GC if the score was $<2$, and positive expression if the score was $\geq 2$.

Cell culture and transfection. GC SGC-7901 cells were cultured in DMEM medium supplemented with $10 \%$ heatinactivated FBS, $100 \mathrm{U} / \mathrm{ml}$ of penicillin and $100 \mu \mathrm{g} / \mathrm{ml}$ of streptomycin. They were all placed in a humidified atmosphere containing $5 \% \mathrm{CO}_{2}$ at $37^{\circ} \mathrm{C}$. Cells were subcultured at a 1:5 dilution in medium containing $300 \mu \mathrm{g} / \mathrm{ml} \mathrm{G} 418$ (an aminoglycoside antibody, commonly used stable transfection reagent in molecular genetic testing). On the day of transduction, GC cells were replated at $5 \times 10^{4}$ cells/well in 24 -well plates containing serum-free growth medium with polybrene $(5 \mathrm{mg} / \mathrm{ml})$. When confluence reached $50 \%$, cells were transfected with recombinant experimental virus or control virus at the optimal MOI (multiplicity of infection) of 50, and cultured at $37^{\circ} \mathrm{C}$ and $5 \% \mathrm{CO}_{2}$ for $4 \mathrm{~h}$. Then supernatant was discarded and serum containing growth medium was added. At 4 days of post-transduction, transduction efficiency was measured by the frequency of green fluorescent protein (GFP)-positive cells. Positive stable transfectants were selected and expanded for further study. The clone in which the Lv-shLivin was transfected was named as shLivin group, the negative control vector transfected was named as NC group, and SGC-7901 cells were named as $\mathrm{CON}$ group.

Quantitative real-time PCR. To quantitatively determine the mRNA expression levels of Livin, VEGF and CAS-3 in GC SGC-7901 cells, real-time PCR was used. Total RNA of each clone was extracted with TRIzol according to the manufacturer's protocol. Reverse-transcription was carried out using M-MLV and cDNA amplification was carried out using SYBR Green Master Mix kit according to the manufacturer's protocol. 
Target genes were amplified using a specific oligonucleotide primer and human glyceraldehyde-3-phosphate dehydrogenase (GAPDH) gene was used as an endogenous control. The PCR primer sequences were as follows: Livin, 5'-CGCACGGCACA AAGACGA-3' and 5'-GTCAGTTCCTGCTCCGGTCAA-3'; p38 MAPK, 5'-AACCTGTCCCCGGTGGGCTCG-3' and 5'-CGATGTCCCGTCTTTGTATGA-3'; VEGF, 5'-GGTGAG AGGTCTAGTTCCCGA-3' and 5'-CCATGAACTTTCTG CTCTTC-3'; MMP-2, 5'-GGCCCTGTCACTCCTGAGAT-3' and 5'-GGCATCCAGGTTATCGGGGA-3'; CAS-3, 5'-CAG ACAGTGGAACTGACGAT-3' and 5'-TTTCAGCATGGC GCAAAGTG-3'; $\beta$-actin, 5'-AGCCATGTACGTAGCCA TCC-3' and 5'-CTCTCAGCTGTGGTGGTGAA-3'. Data were analyzed using the comparative $\mathrm{Ct}$ method $\left(2^{-\Delta \Delta} \mathrm{Ct}\right)$. Three separate experiments were performed for each clone.

Western blot assay. GC SGC-7901 cells were harvested and extracted using lysis buffer (Tris-HCl, SDS, mercaptoethanol, glycerol). Cell extracts were boiled for $5 \mathrm{~min}$ in loading buffer and then equal amount of cell extracts were separated on $15 \%$ SDS-PAGE gels. Separated protein bands were transferred into polyvinylidene fluoride (PVDF) membranes and the membranes were blocked in $5 \%$ skim milk powder. The primary antibodies against Livin, MAPK, p-MAPK, VEGF, MMP-2 and CAS-3 were diluted according to the instructions of antibodies and incubated overnight at $4^{\circ} \mathrm{C}$. Then, horseradish peroxidase-linked secondary antibodies were added at a dilution ratio of 1:1,000, and incubated at room temperature for $2 \mathrm{~h}$. The membranes were washed with PBS three times and the immunoreactive bands were visualized using ECL-PLUS/ kit according to the kit instructions. The relative protein level in different cell lines was normalized to $\beta$-actin concentration. Three separate experiments were performed for each clone.

Fluorescence microscopy. Twenty-four hours after transfection, cells were plated on glass cover slips and $48 \mathrm{~h}$ post transfection the cover slips were washed extensively in phosphate-buffered saline (PBS) and fixed with 4\% paraformaldehyde in PBS. After additional washing, the cells were permeabilized with $1 \%$ Triton X-100 in PBS for 10 min. The cover slips were then washed and blocked with $1 \%$ BSA for $30 \mathrm{~min}$. Cells were incubated in the appropriate primary antibodies (Livin, VEGF and CAS-3) overnight at $4^{\circ} \mathrm{C}$. Samples were then washed and incubated with species-specific secondary rhodamine-labeled antibodies (TRITC) in PBS (1:100 dilution) for $60 \mathrm{~min}$. Nuclei were stained with DAPI at RT for $10 \mathrm{~min}$ and cover slips mounted with Antifade solution prior to imaging on a confocal microscope.

MTT assay. Cell growth in vitro was evaluated using a 3-[4,5-dimethylthiazol-2-yl]-2,5-diphenyltetrazolium bromide (MTT; Sigma) assay. Briefly, $1 \times 10^{4}$ cells were plated in 96-well plates and grown overnight. Twenty microliters of MTT (5 g/l) was added into each well for $4 \mathrm{~h}$. After the medium containing MTT was aspirated, the formazan crystals were dissolved in $200 \mu$ dimethyl sulfoxide. The absorbance was recorded using a Teacan 96-well spectrophotometer at wavelength of $570 \mathrm{~nm}$, using a wavelength of $630 \mathrm{~nm}$ as the reference. Data are presented as the mean $\pm \mathrm{SD}$, derived from triplicate samples of at least three independent experiments.
Transwell invasion assay. Transwell filters were coated with Matrigel (3.9 $\mu \mathrm{g} / \mu \mathrm{l}, 60-80 \mu \mathrm{l})$ on the upper surface of a polycarbonic membrane (diameter $6.5 \mathrm{~mm}$, pore size $8 \mu \mathrm{m}$ ). After incubating at $37^{\circ} \mathrm{C}$ for $30 \mathrm{~min}$, the Matrigel solidified and served as the extracellular matrix for analysis of tumor cell invasion. Harvested cells $\left(1 \times 10^{5}\right)$ in $100 \mu \mathrm{l}$ of serum-free DMEM were added into the upper compartment of the chamber. A total of $200 \mu \mathrm{l}$ conditioned medium derived from NIH3T3 cells was used as a source of chemoattractant and was placed in the bottom compartment of the chamber. After 24-h incubation at $37^{\circ} \mathrm{C}$ with $5 \% \mathrm{CO}_{2}$, the medium was removed from the upper chamber. The non-invaded cells on the upper side of the chamber were scraped off with a cotton swab. The cells that had migrated from the Matrigel into the pores of the inserted filter were fixed with $100 \%$ methanol, stained with hematoxylin, and mounted and dried at $80^{\circ} \mathrm{C}$ for $30 \mathrm{~min}$. The number of cells invading through the Matrigel was counted in three randomly selected visual fields from the central and peripheral portion of the filter using an inverted microscope (x200 magnification). Each assay was repeated three times.

Detection of cell apoptosis. Apoptosis was detected by the TdT-mediated dUTP nick-end labeling (TUNEL) method. Briefly, cells were dewaxed, incubated with blocking solution $\left(0.3 \% \mathrm{H}_{2} \mathrm{O}_{2}\right.$ in double distilled water) for $30 \mathrm{~min}$ and permeabilized with $0.1 \%$ Triton X-100 in PBS for 2 min on ice. Apoptosis was detected using an in-situ cell death kit. Positive cells were visualized by fluorescence microscopy. As a control, the reaction mixture was incubated without enzyme to detect non-specific staining. The apoptotic index was calculated from the ratio of the number of positively stained tumor cells to the total number of tumor cells.

Subcutaneous tumor model and gene therapy. Six-week-old female immune-deficient nude mice (BALB/c-nu) were bred at the Laboratory Animal Facility (Haematology Institute of Chinese Academy of Sciences, Shanghai, China) and were housed individually in microisolator ventilated cages with free access to water and food. All experimental procedures were performed according to the regulations and internal biosafety and bioethics guidelines of Shanghai Jiaotong University and the Shanghai Municipal Science and Technology Commission. Two mice were injected subcutaneously with $1 \times 10^{8}$ GC cells in $50 \mu \mathrm{l}$ of PBS pre-mixed with an equal volume of Matrigel matrix (Becton-Dickinson). Mice were monitored daily and developed a subcutaneous tumor. When the tumor size reached $\sim 5 \mathrm{~mm}$ in length, they were surgically removed, cut into 1-2 $\mathrm{mm}^{3}$ pieces and re-seeded individually into other mice. When tumor size reached $\sim 5 \mathrm{~mm}$ in length, the mice were randomly assigned as PBS group and Lv-shLivin-treated group. In Lv-shLivin group, $15 \mu \mathrm{l}$ of lentivirus was injected into subcutaneous tumors using a multi-site injection format. Injections were repeated every other day after initial treatment. The tumor volume every three days was measured with a caliper, using the formula volume $=(\text { length } \mathrm{x} \text { width })^{2} / 2$.

Statistical analysis. SPSS 20.0 was used for the statistical analysis. Kruskal-Wallis $\mathrm{H}$ test and $\chi^{2}$ test were used to analyze the expression rate in all groups. One-way analysis of variance (ANOVA) was used to analyze the differences between groups. 

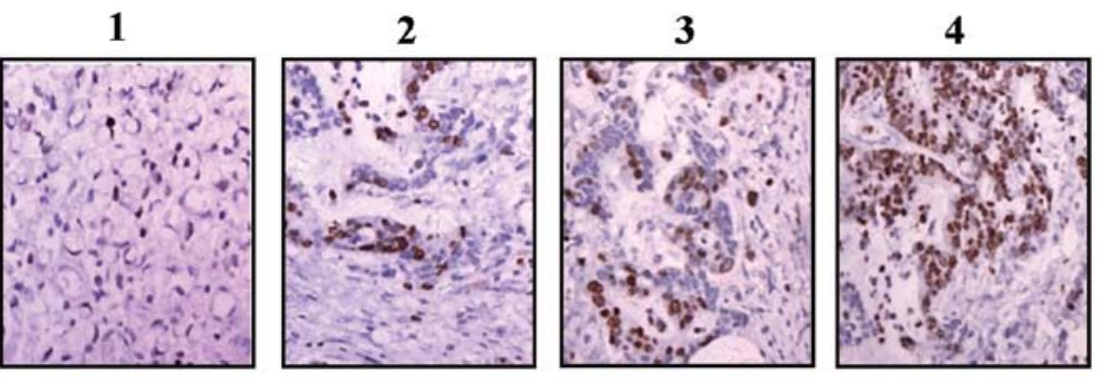

\section{Livin}
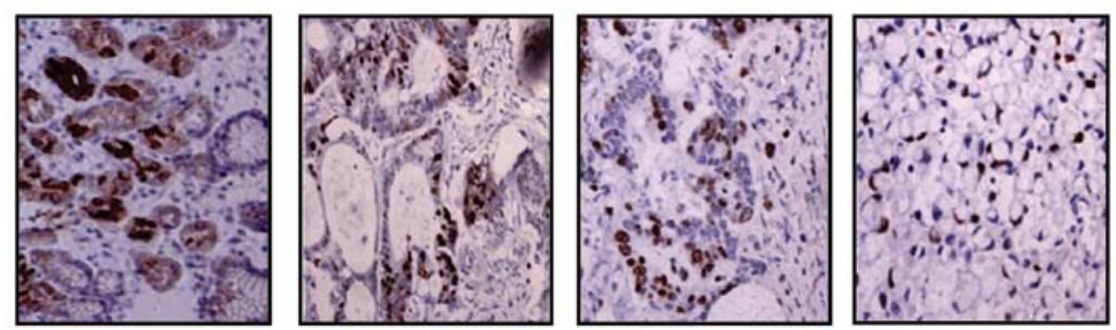

\section{CAS-3}

Figure 1. The expression of Livin and CAS-3 proteins in human GC (x200). The expression of Livin and CAS-3 proteins was examined in different grades of GC by IHC staining. 1, Adjacent non-cancer tissue; 2, well-differentiated gastric cancer tissue; 3, moderately-differentiated gastric cancer tissue; 4, poorlydifferentiated gastric cancer tissue. Livin expression was increased in gastric cancer tissues compared with adjacent non-cancer tissue, elevated with the ascending order of tumor malignancy, while GAS-3 expression was decreased in gastric cancer tissues compared with adjacent non-cancer tissue, lowered with the ascending order of tumor malignancy,

Table I. Expression of Livin and CAS-3 proteins in GC.

\begin{tabular}{lccccccccr}
\hline & & & \multicolumn{7}{c}{$\mathrm{N}$} \\
\cline { 3 - 7 } Target & Group & Total & - & + & ++ & +++ & Positive rate (\%) & $\chi^{2}$ & P-value \\
\hline Livin & GC & 78 & 28 & 20 & 12 & 18 & 64.1 & 13.562 & $<0.001$ \\
& ANCT & 78 & 54 & 8 & 5 & 11 & 30.8 & & \\
CAS-3 & GC & 78 & 52 & 14 & 8 & 4 & 33.3 & 11.478 & 0.001 \\
& ANCT & 78 & 26 & 38 & 11 & 3 & 66.7 & & \\
\hline
\end{tabular}

GC, gastric cancer; ANCT, adjacent non-cancer tissues.

The LSD method of multiple comparisons was used when the probability for ANOVA was statistically significant. Statistical significance was set at $\mathrm{P}<0.05$.

\section{Results}

The expression of Livin and CAS-3 proteins in human GC. The expression of Livin and CAS-3 proteins was examined by IHC staining. Positive staining of Livin was found in the cytoplasm and nucleus, whereas that of CAS-3 protein was mainly observed in the cytoplasm in GC tissues (Fig. 1). As shown in Table I, the positive expression of Livin was detected in $64.1 \%(50 / 78)$ of the GC tissues, and $30.8 \%(24 / 78)$ in a small fraction of ANCT $(\mathrm{P}<0.001)$. In contrast, CAS-3 was found in $66.7 \%(52 / 78)$ of ANCT tissues and $33.3 \%(26 / 78)$ of GC tissues $(\mathrm{P}=0.001)$. Spearman correlation analysis revealed the negative correlation between Livin and CAS-3 expression in GC.

The correlation of Livin and CAS-3 protein expression with clinicopathological characteristics. The association between
Livin and CAS-3 expression and various clinical and histopathological features was analyzed. As shown in Tables II and III, no significant link was found between Livin and CAS-3 expression with the factors including age and gender of the patients, or the size and TNM staging of the tumors (each $\mathrm{P}>0.05)$. However, Livin expression was positively correlated with tumor differentiation and lymph node metastases $(\mathrm{P}=0.009 ; \mathrm{P}=0.007)$, but $\mathrm{CAS}-3$ was negatively associated with them $(\mathrm{P}=0.036 ; \mathrm{P}=0.002)$.

Effect of Livin knockdown on p38 MAPK and p-p38 MAPK expression. To confirm the effect of Livin knockdown on the expression of p38 MAPK and p-p38 MAPK in GC SGC-7901 cells, the mRNA expression levels of Livin and p38 MAPK were measured by real-time PCR. An obvious inhibition of Livin and p38 MAPK mRNA expression was observed in shLivin group compared with the $\mathrm{NC}$ and $\mathrm{CON}$ groups (Fig. 2A, P<0.01). Western blot assay indicated that Livin, p38 MAPK and p-p38 MAPK were found downregulated in shLivin group compared with the $\mathrm{NC}$ and $\mathrm{CON}$ groups) in GC cells (Fig. 2B and C, $\mathrm{P}<0.01$ ). 

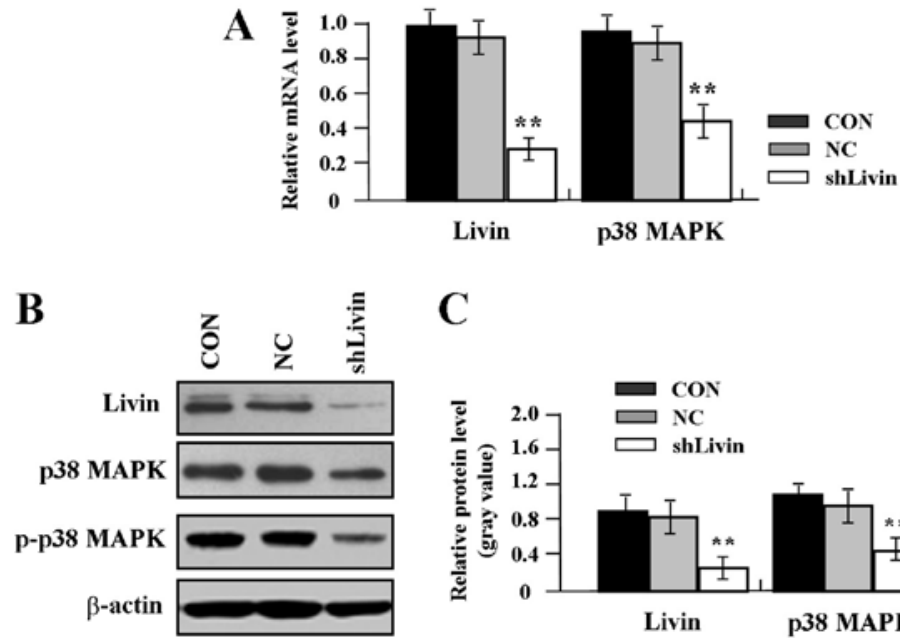

C

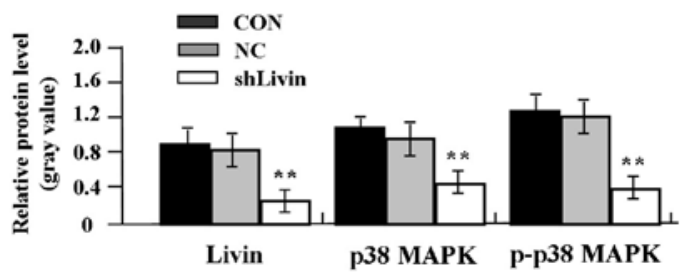

Figure 2. Effect of Livin knockdown on p38 MAPK pathway. (A) After Lv-shLivin was transfected into GC SGC-7901 cells, the mRNA expression levels of Livin and p38 MAPK were measured by real-time PCR, indicating that an obvious inhibition of Livin and p38 MAPK mRNA expression was observed in shLivin group compared with the $\mathrm{NC}$ and $\mathrm{CON}$ groups $\left({ }^{* *} \mathrm{P}<0.01\right.$ ). (B and $\mathrm{C}$ ) Western blot assay showed that knockdown of Livin downregulated the expression of p38 MAPK and p-p38 MAPK in shLivin group compared with the NC and CON groups) in GC cells ( $\left.{ }^{* *} \mathrm{P}<0.01\right)$.

Table II. The correlation of Livin protein with clinicopathological features of patients with GC.

\begin{tabular}{|c|c|c|c|c|}
\hline \multirow[b]{2}{*}{ Variables } & \multirow[b]{2}{*}{ Cases (n) } & \multicolumn{2}{|c|}{$\begin{array}{c}\text { Livin } \\
\text { expression }\end{array}$} & \multirow{3}{*}{ P-value } \\
\hline & & - & + & \\
\hline Total & 78 & 28 & 50 & \\
\hline
\end{tabular}

No. of patients

Age (years)

$\leq 55$

$>55$

25

$\begin{array}{ll}8 & 17\end{array}$

53

$20 \quad 33$

0.624

Sex

Male

$\begin{array}{lll}54 & 19 \quad 35\end{array}$

Female

24

$9 \quad 15$

0.845

Tumor size $(\mathrm{cm})$

$\leq 3.5$

$>3.5$

$\begin{array}{lll}36 & 16 & 20\end{array}$

$42 \quad 12 \quad 30$

0.148

Tumor differentiation

Well + moderately

Poorly

$\begin{array}{lll}32 & 17 & 15\end{array}$

$\begin{array}{lll}46 & 11 & 35\end{array}$

0.009

TNM staging

I+II

III+IV

$\begin{array}{lll}40 & 13 & 27\end{array}$

$\begin{array}{lll}38 & 15 & 23\end{array}$

0.524

Metastatic lymph node

Negative

$\begin{array}{lll}29 & 16 & 13\end{array}$

Positive
Table III. The correlation of CAS-3 protein with clinicopathological features of patients with GC.

\begin{tabular}{lcccc}
\hline & & \multicolumn{3}{c}{$\begin{array}{c}\text { CAS-3 } \\
\text { expression }\end{array}$} \\
\cline { 3 - 4 } & & & \\
\cline { 3 - 4 } Variables & Cases (n) & - & + & P-value \\
Total & 78 & 52 & 26 &
\end{tabular}

No. of patients

Age (years)

$\leq 55$

$>55$

$\begin{array}{ccc}25 & 17 & 8 \\ 53 & 35 & 18\end{array}$

0.865

Sex

Male

Female

$\begin{array}{lll}54 & 34 & 20\end{array}$

$24 \quad 18 \quad 6$

0.301

Tumor size $(\mathrm{cm})$

$$
\leq 3.5
$$

$\begin{array}{lll}36 & 26 & 10\end{array}$

$>3.5$

$\begin{array}{lll}42 & 26 & 16\end{array}$

Tumor differentiation

Well + moderately

$\begin{array}{lll}32 & 17 & 15\end{array}$

$\begin{array}{lll}46 & 35 & 11\end{array}$

0.036

TNM staging

$$
\text { I+II }
$$

III+IV

$\begin{array}{lll}40 & 28 & 12 \\ 38 & 24 & 14\end{array}$

0.524

Metastatic lymph node

Negative

29

49

$\begin{array}{ll}13 & 16 \\ 39 & 10\end{array}$

0.002
Effect of Livin knockdown on VEGF, MMP-2 and CAS-3 expression. To examine the effect of Livin knockdown on the expression of VEGF, MMP-2 and CAS-3 in GC cells,
GC SGC-7901 cells were transfected with Lv-shLivin. The mRNA expression levels of VEGF, MMP-2 and CAS-3 were evaluated by quantitative real-time PCR (Fig. 3A) and their 


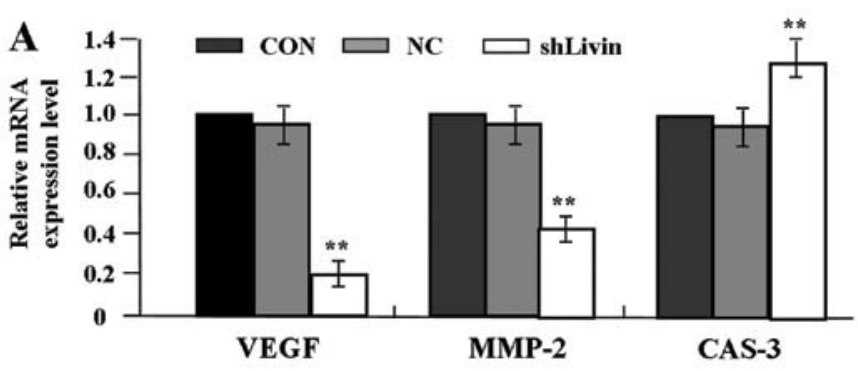

B
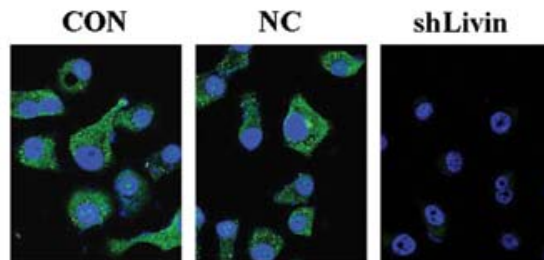

VEGF
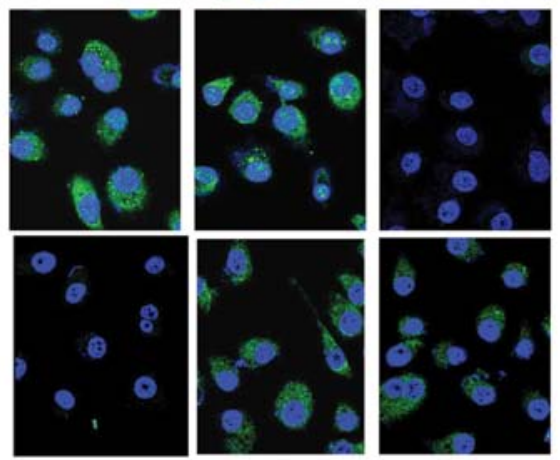

Figure 3. Effect of Livin knockdown on VEGF, MMP-2 and CAS-3 expression. After Lv-shLivin was transfected into GC SGC-7901 cells, the mRNA expression levels of VEGF, MMP-2 and CAS-3 were assessed by quantitative real-time PCR (A) and their protein expression was identified by fluorescence microscopy (B). The expression levels of VEGF and MMP-2 were decreased, while that of CAS-3 was increased in shLivin group compared with the NC and CON groups $\left(\right.$ each $\left.^{* *} \mathrm{P}<0.01\right)$. protein expression was identified by fluorescence microscopy (Fig. 3B). The expression levels of VEGF and MMP-2 were decreased, while that of CAS-3 was increased in shLivin group compared with the $\mathrm{NC}$ and $\mathrm{CON}$ groups (each $\mathrm{P}<0.01$ ).

Effect of Livin knockdown on cell proliferation and invasion. To gain knowledge on the effect of Livin knockdown on tumor growth and invasion in GC SGC-7901 cells, we assessed cell proliferative activities by MTT assay and cell invasive potential by Transwell assay. It was found that Livin knockdown markedly suppressed cell proliferative activities in a time-dependent manner (Fig. 4A) and cell invasive potential (Fig. 5A and B) in GC cells compared with $\mathrm{NC}$ and $\mathrm{CON}$ groups (each $\mathrm{P}<0.01$ ). In addition, we detected the protein expression of VEGF (Fig. 4B and C) and MMP-2 (Fig. 5C and D) by western blot assay to determine whether Livin knockdown affected their expression through translational repression. It was shown that the amount of VEGF and MMP-2 proteins was significantly decreased in shLivin group compared with $\mathrm{NC}$ and $\mathrm{CON}$ groups $(\mathrm{P}<0.01)$.

Effect of Livin knockdown on cell apoptosis. To evaluate whether Livin knockdown influenced cell in situ apoptosis, TUNEL method was performed. Cell apoptotic index in shLivin group was remarkably increased compared with the $\mathrm{NC}$ and $\mathrm{CON}$ groups (Fig. 6A and $\mathrm{B}, \mathrm{P}<0.01$ ). We detected the protein expression of CAS-3 (Fig. 6C and D) by western blot assay to determine the effect of Livin knockdown on CAS-3 expression through translational repression. It was shown that the amount of CAS-3 protein was significantly increased in shLivin group compared with $\mathrm{NC}$ and $\mathrm{CON}$ groups $(\mathrm{P}<0.01)$.

Antitumor effect of Lv-shLivin on SGC-7901 xenograft model. Our in vitro experiments demonstrated that knockdown of
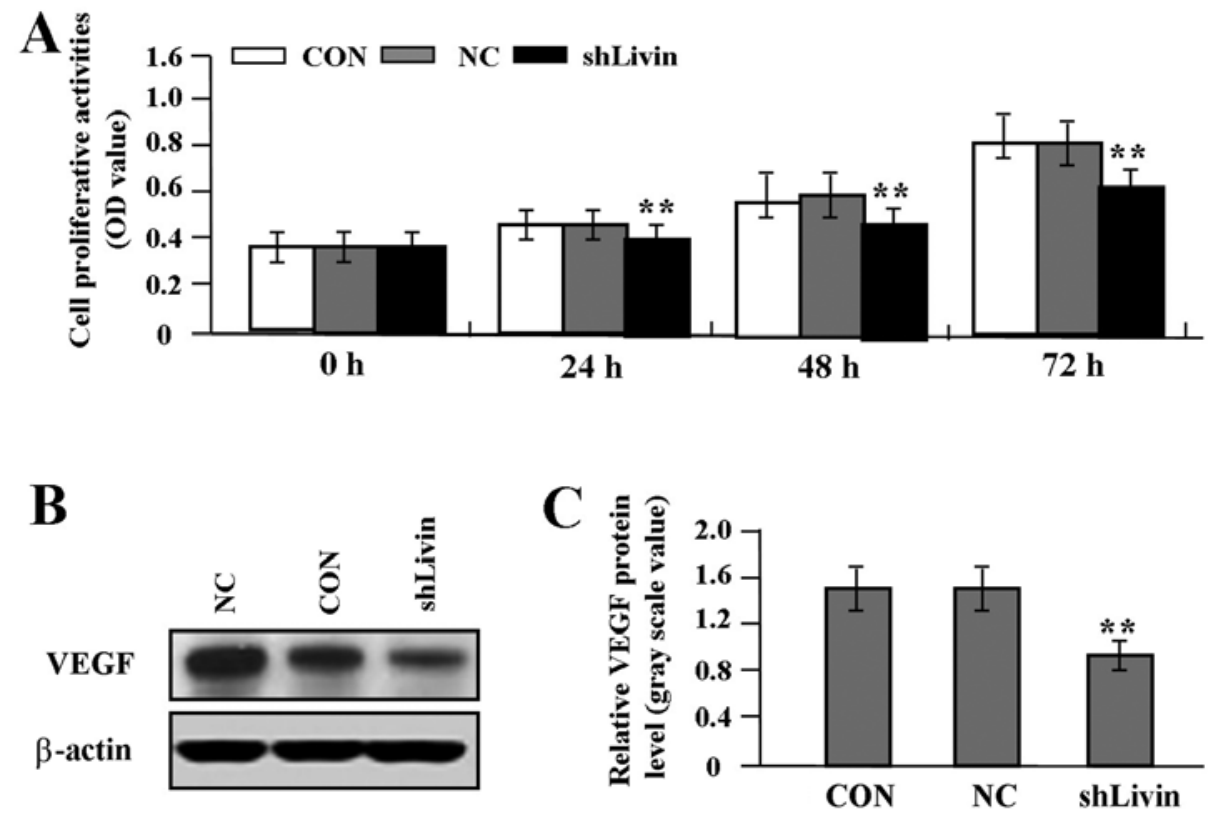

Figure 4. Effect of Livin knockdown on cell proliferation. (A) MTT assay was to investigate the proliferative activities of GC SGC-7901 cells and indicated that knockdown of Livin significantly diminished proliferative activities of GC cells in a time-dependent manner (each $\left.{ }^{* *} \mathrm{P}<0.01\right)$. (B and C) The amount of VEGF protein, indicated by western blot assay, was significantly decreased in shLivin group compared with the NC and CON groups $\left({ }^{* *} \mathrm{P}<0.01\right)$. 

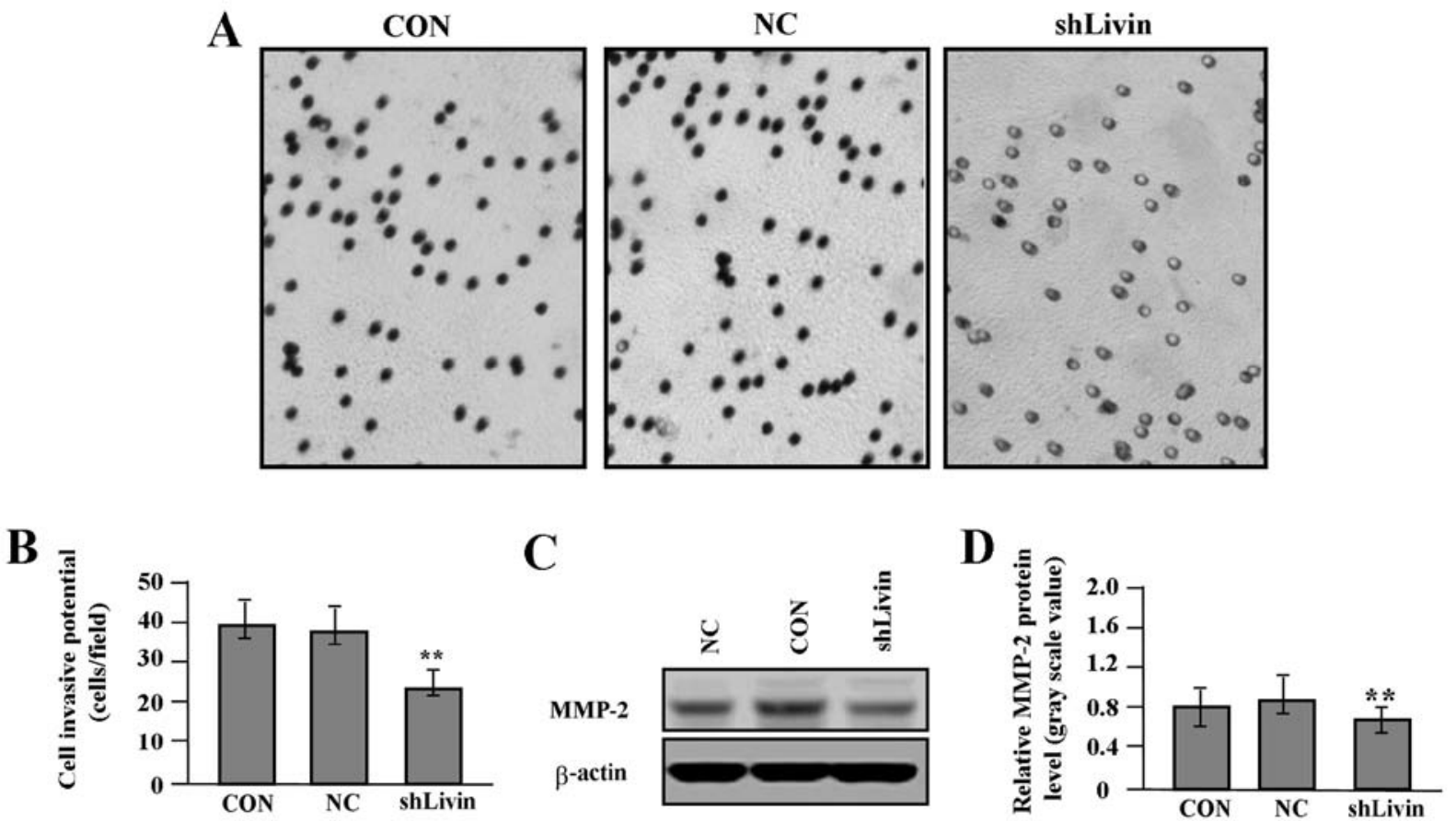

Figure 5. Effect of Livin knockdown on cell invasion (x200). (A and B) Transwell assay was carried out to determine the invasive potential of GC cells, which was significantly decreased in shLivin group compared with $\mathrm{NC}$ and $\mathrm{CON}$ groups $\left({ }^{* *} \mathrm{P}<0.01\right)$. (C and $\left.\mathrm{D}\right)$ The amount of MMP- 2 protein, indicated by western blot assay, was significantly decreased in shLivin group compared with the $\mathrm{NC}$ and $\mathrm{CON}$ groups $\left({ }^{* *} \mathrm{P}<0.01\right)$.
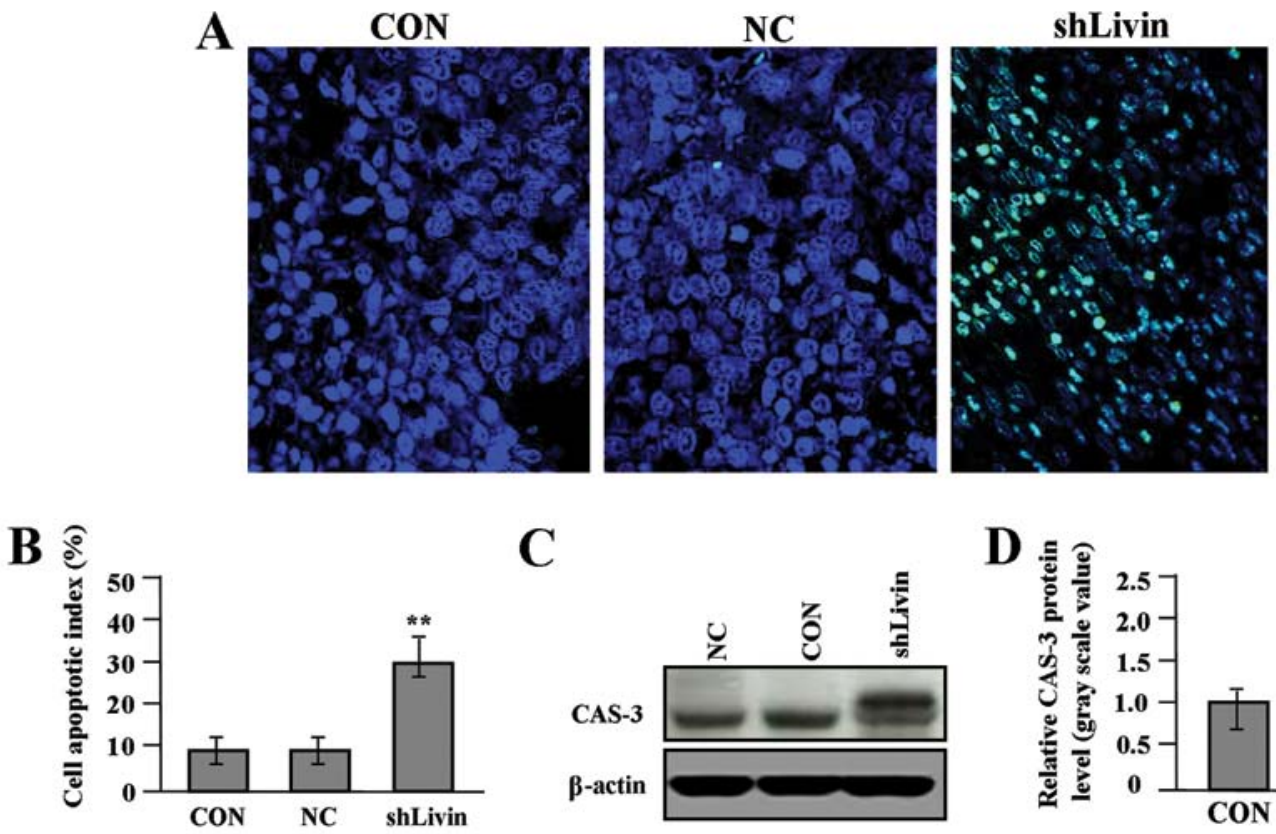

C

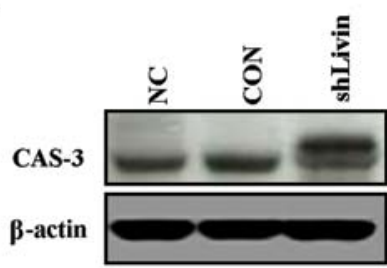

D

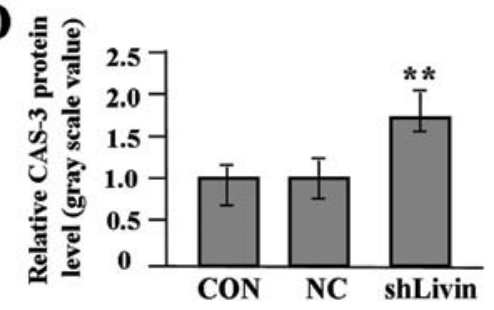

Figure 6. Effect of Livin knockdown on cell apoptosis (x200). (A and B) TUNEL assay was performed to analyze the apoptotic indexes of GC cells, which were significantly reduced in shLivin group compared with $\mathrm{NC}$ and $\mathrm{CON}$ groups $\left({ }^{* *} \mathrm{P}<0.01\right)$. (C and D) The amount of CAS-3 protein, indicated by western blot assay, was significantly increased in shLivin group compared with the NC and CON groups $\left({ }^{* *} \mathrm{P}<0.01\right)$.

Livin could efficiently inhibit proliferation and invasion in GC SGC-7901 cells. Therefore, we further investigated antitumor effect of Lv-shLivin in vivo using the SGC-7901 xenograft model and letivirus-mediated gene therapy. The mean volume of tumors in all experimental mice before treatment was $38.20 \pm 9.40 \mathrm{~mm}^{3}$. Each mouse was challenged by in situ injec- tion of PBS (control; $n=4)$, or Lv-shLivin ( $n=4)$. During the first two weeks recovery, the tumors in Lv-shLivin group grew slowly compared with $\mathrm{NC}$ group (Fig. 7A and C). There was a significant difference in tumor volumes and weight between Lv-shLivin group and PBS group over the observation period $(\mathrm{P}<0.01)$ (Fig. 7B and $\mathrm{D})$. 
A

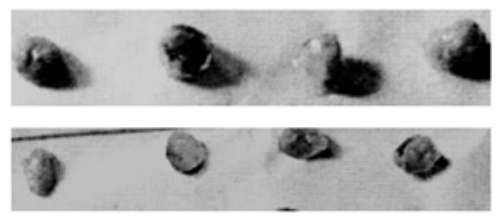

PBS

shLivin
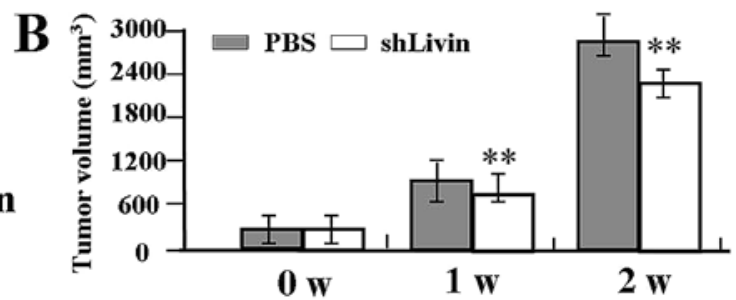

D

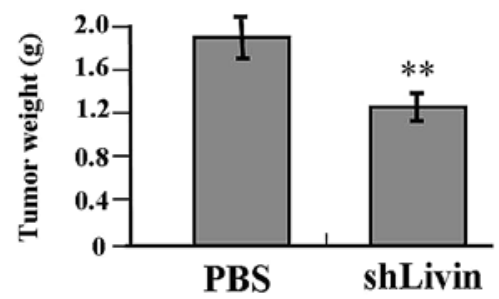

Figure 7. Antitumor effect of Lv-shLivin on the SGC-7901 xenograft model. (A and C) During the first two weeks of recovery, the tumors grew slowly in Lv-shLivin group compared with the NC group. (B and D) The tumor volumes and weight were much smaller in shLivin group than those in PBS group over the observation period $\left({ }^{* *} \mathrm{P}<0.01\right)$.

\section{Discussion}

Livin, a member of the IAP family, plays crucial roles in apoptosis, cell proliferation and cell cycle control. Abnormal Livin expression is detected during the process of cancer formation and progression (18). Livin is highly expressed in CRC tissues, and may influence the prognosis of CRC as a biomarker or potential therapeutic target (19). Livin is also expressed in $75 \%$ of bladder cancer, and its detection in bronchial aspirates shows $63 \%$ sensitivity and $92 \%$ specificity, suggesting that Livin may be valuable diagnostic marker for the early diagnosis of lung cancer (20) and predict early recurrence in invasive bladder cancer (21). Thus, Livin research may provide an opportunity for the development of potential therapy for Livin-relevant cancers.

Interestingly, Livin is a member of CAS inhibitors that selectively binds the endogenous CAS-3 (22). It is negatively associated with CAS-3 expression and contributes to the tumor progression (23). To further clarify the clinical significance of Livin and CAS-3 in GC, in the present study, our findings showed that, Livin expression was increased, while CAS-3 was decreased in human GC tissues compared to the ANCT. Moreover, Livin expression was positively correlated with tumor differentiation and lymph node metastases, but CAS-3 was negatively associated with them, which has been confirmed by Wang et al (24) and Liang et al (25). In addition, as for the cellular localization, the positive expression of Livin and CAS-3 was mainly localized in the cytoplasm, suggesting that cytoplasmic accumulation of Livin may contribute to the development of GC.

In regard to the function of Livin in cancer, some studies have demonstrated that Livin promotes tumor cell proliferation by regulating G1-S cell cycle transition (26) and mediates cell invasion via nuclear NF- $\mathrm{BB}$ signaling (27). Inversely, silencing Livin gene leads to apoptosis induction, cell cycle arrest and proliferation inhibition in malignant tumor cells (28-30). However, few reports have shown the function of Livin in GC.
To confirm the effect of Livin knockdown on GC cells, the present study showed that knockdown of Livin inhibited cell proliferation and the invasive potential, and induced cell apoptosis in GC cells in vitro and in vivo, suggesting that Livin might serve as a novel therapeutic target for the treatment of GC.

Accumulating data indicate that VEGF participates in the pathogenesis of many neoplastic diseases, and correlates with aggressiveness and prognosis as a tumor biomarker for tumor invasion (31). However, there is little evidence demonstrating the direct regulation of Livin on VEGF expression in GC cells. Knockdown of Livin inhibits cell invasion via decrease of MMP-2/-9 expression in osteosarcoma cells (32). Regarding the effect of Livin on CAS-3 expression, antisense oligonucleotide targeting Livin induces apoptosis of human bladder cancer cell with increased expression of CAS-3 (33). In the present study, our findings showed that knockdown of Livin downregulated the expression of VEGF and MMP-2, but upregulated the expression of CAS-3 in GC cells. Moreover, our finding indicated that knockdown of Livin decreased the activity of MAPK signaling in GC cells, while MAPK upregulates MMP-2 and VEGF expression and downregulates CAS-3 expression in cancer cells (34-36), suggesting that Livin may be implicated in the development and progression of GC cells possibly via regulation of MAPK signaling-mediated VEGF, MMP-2 and CAS-3 expression.

Overall, our findings indicate that the expression of Livin is increased in human GC and correlates with tumor differentiation and lymph node metastases, while knockdown of Livin inhibits cell growth and invasion through blockade of the MAPK pathway in GC cells in vitro and in vivo, suggesting that Livin may be a potential therapeutic target for the treatment of GC.

\section{Acknowledgements}

This study was supported by Shanghai Science and Technology Committee Scientific and Technological Innovation Project 
(no. 12140901102) and Shanghai City Board of Education Research and Innovation Project (no. 12YZ042).

\section{References}

1. Jemal A, Bray F, Center MM, et al: Global cancer statistics. CA Cancer J Clin 61: 69-90, 2011.

2. Tajima Y, Yamazaki K, Makino R, et al: Gastric and intestinal phenotypic marker expression in early differentiated-type tumors of the stomach: clinicopathologic significance and genetic background. Clin Cancer Res 12: 6469-6479, 2006

3. Hartman ML and Czyz M: Anti-apoptotic proteins on guard of melanoma cell survival. Cancer Lett 331: 24-34, 2013.

4. Kim DK, Alvarado CS, Abramowsky CR, et al: Expression of inhibitor-of-apoptosis protein (IAP) livin by neuroblastoma cells: correlation with prognostic factors and outcome. Pediatr Dev Pathol 8: 621-629, 2005.

5. Kleinberg L, Lie AK, Flørenes VA, et al: Expression of inhibitorof-apoptosis protein family members in malignant mesothelioma. Hum Pathol 38: 986-994, 2007.

6. Nedelcu T, Kubista B, Koller A, et al: Livin and Bcl-2 expression in high-grade osteosarcoma. J Cancer Res Clin Oncol 134 237-244, 2008

7. Lazar I, Perlman R, Lotem M, et al: The clinical effect of the inhibitor of apopotosis protein livin in melanoma. Oncology 82: 197-204, 2012

8. Liu HB, Kong CZ, Zeng Y, et al: Livin may serve as a marker for prognosis of bladder cancer relapse and a target of bladder cancer treatment. Urol Oncol 27: 277-283, 2009.

9. Liu H, Wang S, Sun H, et al: Inhibition of tumorigenesis and invasion of hepatocellular carcinoma by siRNA-mediated silencing of the livin gene. Mol Med Rep 3: 903-907, 2010.

10. Crnković-Mertens I, Bulkescher J, Mensger C, et al: Isolation of peptides blocking the function of anti-apoptotic Livin protein. Cell Mol Life Sci 67: 1895-1905, 2010.

11. Wang X, Xu J, Ju S, et al: Livin gene plays a role in drug resistance of colon cancer cells. Clin Biochem 43: 655-660, 2010.

12. Dasgupta A, Alvarado CS, Xu Z, et al: Expression and functional role of inhibitor-of-apoptosis protein livin (BIRC7) in neuroblastoma. Biochem Biophys Res Commun 400: 53-59, 2010.

13. Ding ZY, Liu GH, Olsson B, et al: Upregulation of the antiapoptotic factor Livin contributes to cisplatin resistance in colon cancer cells. Tumour Biol 234: 683-693, 2013.

14. Sun JG, Liao RX, Zhang SX, et al: Role of inhibitor of apoptosis protein Livin in radiation resistance in nonsmall cell lung cancer. Cancer Biother Radiopharm 26: 585-592, 2011.

15. Abd-Elrahman I, Hershko K, Neuman T, et al: The inhibitor of apoptosis protein Livin (ML-IAP) plays a dual role in tumorigenicity. Cancer Res 69: 5475-5480, 2009.

16. Kempkensteffen C, Hinz S, Christoph F, et al: Expression of the apoptosis inhibitor livin in renal cell carcinomas: correlations with pathology and outcome. Tumour Biol 28: 132-138, 2007.

17. Dai CH, Li J, Shi SB, et al: Survivin and Smac gene expressions but not livin are predictors of prognosis in non-small cell lung cancer patients treated with adjuvant chemotherapy following surgery. Jpn J Clin Oncol 40: 327-335, 2010.

18. Yan B: Research progress on Livin protein: an inhibitor of apoptosis. Mol Cell Biochem 357: 39-45, 2011.

19. Xi RC, Biao WS and Gang ZZ: Significant elevation of survivin and livin expression in human colorectal cancer: inverse correlation between expression and overall survival. Onkologie 34 $428-432,2011$
20. Li J, Chen P, Li XQ, et al: Elevated levels of survivin and livin mRNA in bronchial aspirates as markers to support the diagnosis of lung cancer. Int J Cancer 132: 1098-1104, 2013.

21. Xi RC, Sheng YR, Chen WH, et al: Expression of survivin and livin predicts early recurrence in non-muscle invasive bladder cancer. J Surg Oncol 107: 550-554, 2012.

22. Chang $\mathrm{H}$ and Schimmer AD: Livin/melanoma inhibitor of apoptosis protein as a potential therapeutic target for the treatment of malignancy. Mol Cancer Ther 6: 24-30, 2007.

23. Li H, Chen Y, Chen G, et al: Expression of livin in lung cancer tissue and its relationship with the expression of caspase-3. Zhongguo Fei Ai Za Zhi 10: 486-490, 2007.

24. Wang TS, Ding QQ, Guo RH, et al: Expression of livin in gastric cancer and induction of apoptosis in SGC-7901 cells by shRNAmediated silencing of livin gene. Biomed Pharmacother 64: 333-338, 2010.

25. Liang YZ, Fang TY, Xu HG, et al: Expression of CD44v6 and Livin in gastric cancer tissue. Chin Med J 125: 3161-3165, 2012.

26. Ye L, Song X, Li S, et al: Livin- $\alpha$ promotes cell proliferation by regulating G1-S cell cycle transition in prostate cancer. Prostate 71: 42-51, 2011.

27. Chen F, Yang D, Che X, et al: Livin mediates tumor cell invasion in the DU-145 cell line via NF-кB. Oncol Rep 27: 2010-2016, 2012.

28. Wang H, Tan SS, Wang XY, et al: Silencing livin gene by siRNA leads to apoptosis induction, cell cycle arrest, and proliferation inhibition in malignant melanoma LiBr cells. Acta Pharmacol Sin 28: 1968-1974, 2007.

29. Yang D, Song X, Zhang J, et al: Suppression of livin gene expression by siRNA leads to growth inhibition and apoptosis induction in human bladder cancer T24 cells. Biosci Biotechnol Biochem 74: 1039-1044, 2010.

30. Yuan B, Ran B, Wang S, et al: siRNA directed against Livin inhibits tumor growth and induces apoptosis in human glioma cells. J Neurooncol 107: 81-87, 2012.

31. Kajdaniuk D, Marek B, Fołtyn W, et al: Vascular endothelial growth factor (VEGF) in endocrinology and oncology. Endokrynol Pol 62: 14-22, 2011.

32. Li X, Fan S, Li L, et al: RNA interference-mediated knockdown of Livin suppresses cell proliferation and invasion and enhances the chemosensitivity to cisplatin in human osteosarcoma cells. Int J Oncol 43: 159-168, 2013

33. Liu C, Wu X, Luo C, et al: Antisense oligonucleotide targeting Livin induces apoptosis of human bladder cancer cell via a mechanism involving caspase 3. Exp Clin Cancer Res 29: 63, 2010.

34. Shin I, Kim S, Song H, et al: H-Ras-specific activation of Rac-MKK3/6-p38 pathway: its critical role in invasion and migration of breast epithelial cells. Biol Chem 280: 14675-14683, 2005.

35. Hideshima T, Akiyama M, Hayashi T, et al: Targeting p38 MAPK inhibits multiple myeloma cell growth in the bone marrow milieu. Blood 101: 703-705, 2003.

36. Noguchi K, Yamana H, Kitanaka C, et al: Differential role of the JNK and p38 MAPK pathway in c-Myc- and s-Mycmediated apoptosis. Biochem Biophys Res Commun 267: 221-227, 2000 